\title{
Stimulation of Titanium Implant Osseointegration Through High-Frequency Vibration Loading is Enhanced when Applied at High Acceleration
}

Toru Ogawa ${ }^{1,2}$, Katleen Vandamme ${ }^{1}$, Xiaolei Zhang ${ }^{1,3}$, Ignace Naert ${ }^{1}$, Tine Possemiers ${ }^{1}$, Amol Chaudhari ${ }^{1}$, Keiichi Sasaki ${ }^{2}$ and Joke Duyck ${ }^{1}$

(1)

BIOMAT KU Leuven, Department of Oral Health Sciences \& Dental Clinic, KU Leuven \& University Hospitals Leuven, Kapucijnenvoer 7, P.O. Box 7001, 3000 Leuven, Belgium

(2)

Division of Advanced Prosthetic Dentistry, Tohoku University Graduate School of Dentistry, Sendai, Japan

(3)

Guanghua School of Stomatology, Hospital of Stomatology, Sun Yat-sen University, Guangzhou, China

Joke Duyck

Email: Joke.Duyck@uzleuven.be

Received: 4 June 2013Accepted: 28 June 2013Published online: 11 September 2014

\begin{abstract}
Low-magnitude high-frequency loading, applied by means of whole body vibration (WBV), affects the bone. Deconstructing a WBV loading stimulus into its constituent elements and investigating the effects of frequency and acceleration individually on bone tissue kinetics around titanium implants were aimed for in this study. A titanium implant was inserted in the tibia of 120 rats. The rats were divided into 1 control group (no loading) and 5 test groups with low $(\mathrm{L})$, medium $(\mathrm{M})$ or high $(\mathrm{H})$ frequency ranges and accelerations $[12-30 \mathrm{~Hz}$ at $0.3 \times \mathrm{g}$ $\left(\mathrm{F}_{\mathrm{L}} \mathrm{A}_{\mathrm{H}}\right) ; 70-90 \mathrm{~Hz}$ at $0.075 \times \mathrm{g}\left(\mathrm{F}_{\mathrm{M}} \mathrm{A}_{\mathrm{M}}\right) ; 70-90 \mathrm{~Hz}$ at $0.3 \times \mathrm{g}\left(\mathrm{F}_{\mathrm{M}} \mathrm{A}_{\mathrm{H}}\right) ; 130-150 \mathrm{~Hz}$ at $0.043 \times \mathrm{g}\left(\mathrm{F}_{\mathrm{H}} \mathrm{A}_{\mathrm{L}}\right) ; 130-150 \mathrm{~Hz}$ at $\left.0.3 \times \mathrm{g}\left(\mathrm{F}_{\mathrm{H}} \mathrm{A}_{\mathrm{H}}\right)\right]$. WBV was applied for 1 or 4 weeks. Implant osseointegration was evaluated by quantitative histology (bone-to-implant contact (BIC) and peri-implant bone formation (BV/TV)). A 2-way ANOVA (duration of experimental period; loading mode) with $\alpha=0.05$ was performed. BIC significantly increased over time and under load ( $<<0.0001)$. The highest BICs were found for loading regimes at high acceleration with medium or high frequency ( $\mathrm{F}_{\mathrm{M}} \mathrm{A}_{\mathrm{H}}$ and $\mathrm{F}_{\mathrm{H}} \mathrm{A}_{\mathrm{H}}$ ), and significantly differing from $\mathrm{F}_{\mathrm{L}} \mathrm{A}_{\mathrm{H}}$ and $\mathrm{F}_{\mathrm{M}} \mathrm{A}_{\mathrm{M}}(\mathrm{p}<0.02$ and $\mathrm{p}<0.005$ respectively). BV/TV significantly decreased over time $(\mathrm{p}<0.0001)$. Loading led to a site-specific BV/TV increase $(p<0.001)$. The highest BV/TV responses were found for $F_{M} A_{H}$ and $F_{H} A_{H}$, significantly differing from $F_{M} A_{M}(p<0.005)$. The findings reveal the potential of high-frequency vibration loading to accelerate and enhance implant osseointegration, in particular when applied at high acceleration. Such mechanical signals hold great, though untapped, potential to be used as non-pharmacologic treatment for improving implant osseointegration in compromised bone.
\end{abstract}


Keywords

Titanium implant osseointegration Whole body vibration Frequency Acceleration Rat tibia

Toru Ogawa and Katleen Vandamme shared first authorship.

\section{Introduction}

Low-magnitude high-frequency (LMHF) mechanical loading, applied by means of whole body vibration (WBV), affects the skeleton $[1,2]$. Ample evidence is provided that LMHF WBV loading stimulates bone formation [2] and bone healing [므요. WBV loading has therefore been introduced in the clinics as a non-pharmacological intervention in the treatment of e.g. osteoporosis [ㅁ-13]. As titanium implant osseointegration implicates bone healing [14, 15], it was anticipated that LMHF loading has the potential to positively affect peri-implant bone healing and ultimately implant osseointegration. Results of a previous study performed by the authors' group using the rat tibia implant model and applying LMHF WBV loading immediately after implant installation confirmed the anabolic capacity of this loading mode in the establishment of titanium implant osseointegration [16]. Moreover, in compromised bone situations such as in ovariectomized (OVX) rats, it has been observed that the application of LMHF WBV loading enhances bone-implant osseointegration [ $\underline{17}, \underline{18}]$.

The specific parameters of a loading regime, such as duration, session distribution, frequency and amplitude of loading, play an important role in the impact of LMHF loading on bone. In order to gain a better understanding into the exact contribution of the component(s) that control the bone response to LMHF loading, efforts have been made on deconstructing the dynamic loading cycle into its constituent elements and investigating their effects individually on bone tissue kinetics [19-23]. However, this is poorly explored for the peri-implant setting. The impact of the duration of loading and the loading session (bouts) distribution (single-bout vs. partitioned application) was assessed in another study of our group [24]. A significant effect of the duration of LMHF WBV application on peri-implant bone healing and implant osseointegration was found, with longer loading periods being more osteogenic. Moreover, the introduction of a rest period between the loading sessions (partitioned load application) further enhanced the osteogenic response. LMHF loading that is applied twice for a short period (1.25 min) with a 4-h interval rest appeared to have the most pronounced anabolic effect [24].

Besides loading duration and distribution, also the frequency and amplitude of the WBV exposure are determinants of the bone response. The amplitude (magnitude) of a vibration can be quantified by its displacement, its velocity or its acceleration. For practical convenience, the amplitude of vibration is mostly expressed in terms of an average measure of the acceleration of the oscillatory motion, as measured by an accelerometer. The acceleration is defined by the frequency and the oscillatory displacement of the object, and is expressed in $\mathrm{m} \mathrm{s}^{-2}$. The acceleration is often denoted in terms of $\mathrm{g}$, with $\mathrm{g}$ being the acceleration due to the Earth's gravity $\left(1 \times \mathrm{g}=9.81 \mathrm{~m} \mathrm{~s}^{-2}\right)$. Since most WBV platforms allow for multiple settings of frequency and amplitude of displacement, there are many possible combinations and resulting accelerations. The study of Judex et al. [20], aiming to investigate the role of the vibration frequency (45 vs. $90 \mathrm{~Hz}$ ) in a low-magnitude WBV regime $(0.15 \times \mathrm{g})$ in OVX rats, revealed that the efficacy of WBV was strongly dependent on the frequency of the applied signal (in favour for $90 \mathrm{~Hz}$ ) but independent of the induced bone strains (significantly higher strains were recorded for the $45 \mathrm{~Hz}$ regime compared to $90 \mathrm{~Hz}$ vibration). The authors of the referred paper suggested that the optimization of a WBV intervention should not focus on the induced bone strains, but rather on the bone cells' frequency-specific sensitivity relative to the loading duration and acceleration. Oxlund et al. [21]) demonstrated, in a similar experimental set-up 
with OVX rats, that vibrations applied at $17 \mathrm{~Hz}(0.5 \times \mathrm{g}), 30 \mathrm{~Hz}(1.5 \times \mathrm{g})$ or $45 \mathrm{~Hz}(3 \times \mathrm{g})$ are all sensed in the cortical bone. The stimulation at the highest frequency and with the highest acceleration was shown to be most effective in enhancing cellular activity, and was actually the only one preventing the loss of cortical bone strength. The selective effects of different frequency and acceleration parameters on the bone and muscle response are starting to become clear [25-28]. However, their roles in enhancing titanium implant healing and osseointegration have not been reported so far, and are the strategy of the presented research. Six experimental groups with WBV at low-, medium- or high-frequency ranges and at low, medium or high acceleration were designed. It was hypothesized that (i) WBV loading is anabolic for titanium implant osseointegration, and that (ii) the most pronounced response of the peri-implant bone to WBV would be obtained for the loading regime at highest frequency and acceleration. The aim of this study was to indicate the optimal combination of frequency and acceleration parameters stimulating titanium implant osseointegration. Therefore, the expected findings may be of considerable importance in establishing new loading protocols to enhance implant osseointegration, particularly in compromised bone conditions.

\section{Materials and Methods}

\section{Animals and Surgical Procedure}

The study was carried out on 120 male Wistar rats (3 months old) with an average weight of 353.1×g (SD: \pm 11.7 ). Custom-made cylindrical screw-type implants (Ø: 2 mm; L: 10 mm) were obtained from a titanium rod (99.6 \% Ti, Goodfellow Cambridge Ltd., Huntingdon, England) (Fig. 1a). Prior to installation, the implants were cleaned in an ultrasonic bath and decontaminated with a mixture of HF (4\%) and HNO3 (20\%). 3D topographical analysis of the implant surface was performed using a scanning white light interferometer at the vertical shifting interferometry mode (Wyko NT 3300; Veeco Metrology Inc., Tucson, USA). Analyses $(n=12)$ were performed at the implant part devoid of screw threads. The etched implant surface was characterized by a roughness (Sa) of $224.5 \mathrm{~nm}( \pm 13.4)$ and a developed interfacial area ratio (Sdr) of $1 \%$. Implants were sterilized by autoclaving prior to insertion in the tibia unilaterally (left and right tibia randomized).
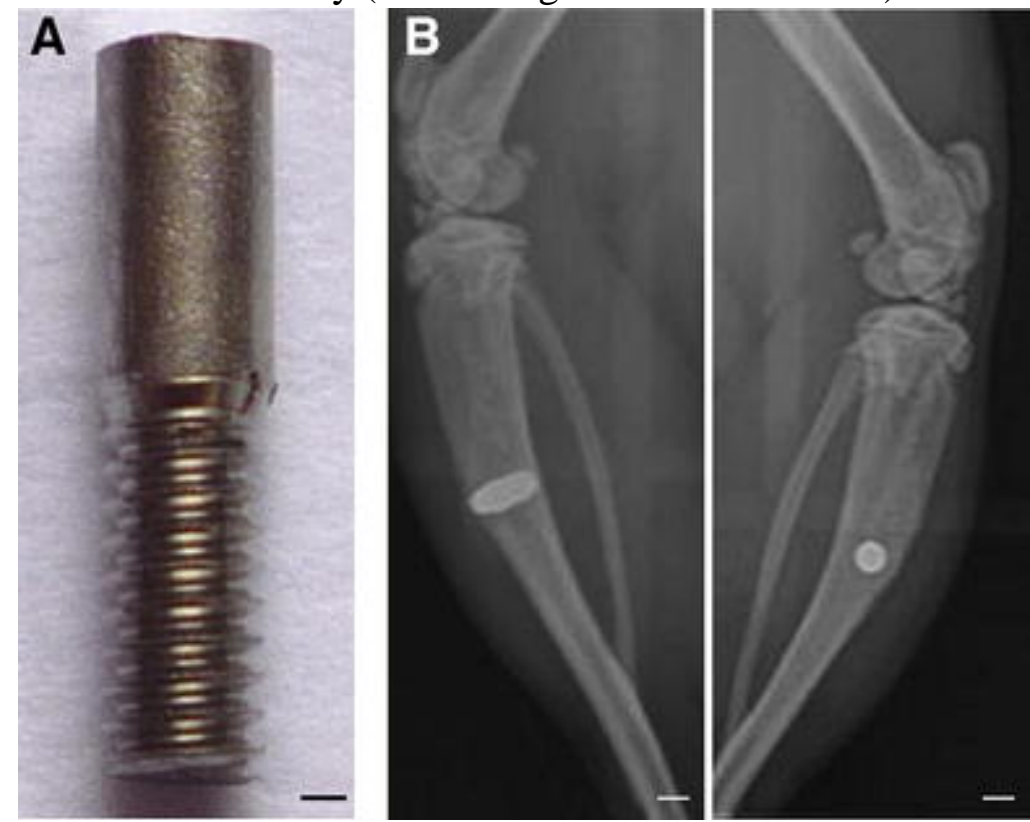

Fig. 1 
Custom-made titanium implant (a scale bar: $0.5 \mathrm{~mm}$ ), in situ at the metaphyseal region of the proximal side of the tibia (b scale bar: $2 \mathrm{~mm}$ )

The rats were anesthetized with $2.5 \%$ Isoflurane (Isoflurane USP ${ }^{\circledR}$, Halocarbon, NJ, USA). The medial aspect of the metaphyseal region of the proximal (i.e. near the tibial condyle) side of the tibia was exposed by dissection. Perpendicular to the tibia's long axis and at a standardized position (i.e. at the junction of the tibia's upper and middle third at the level of the soleal line), a cavity was drilled under constant saline cooling. Both the medial and the lateral bone cortices were perforated (Fig. 1b). In order to achieve good primary stability, the final surgical drill used was $0.3 \mathrm{~mm}$ undersized compared to the implant's external diameter. After manual implant insertion by means of a custom-fit wrench, the wound was closed with resorbable sutures (Vicryl ${ }^{\circledR}$ 3-0, Ethicon, USA), fully submerging the implant. Analgesics were given post-operatively for 2 days by intramuscular injection of buprenorphine (Temgesic ${ }^{\circledR}$ at $0.05 \mathrm{mg} / \mathrm{kg}$, Reckitt Benckiser, Brussels, Belgium). The animals were euthanatized by cervical displacement under isoflurane-induced anaesthesia at the end of the experiment.

\section{Whole Body Vibration Loading Protocols}

The LMHF loading was applied by means of a custom-made WBV device (Department of Mechanical Engineering, Division of Biomechanics and Engineering Design, KU Leuven, Belgium) [ $\underline{16}, 24]$. The animals were randomly divided into 2 groups with different experimental periods. In one group $(n=60)$, the experiment lasted for 1 week, while in the other group $(n=60)$ for 4 weeks. Each group was subdivided into 6 groups: one unloaded control group (CTR) and 5 WBV loaded groups. Attempting to cover a wide range of periimplant bone reactions, specific combinations of frequency ranges (classified as 'low $\left(\mathrm{F}_{\mathrm{L}}\right)$ ', 'medium $\left(\mathrm{F}_{\mathrm{M}}\right)$ ' or 'high $\left(\mathrm{F}_{\mathrm{H}}\right)$ ') and peak accelerations (classified as 'low $\left(\mathrm{A}_{\mathrm{L}}\right)$ ', 'medium (A $\mathrm{M})$ ' or 'high $\left(\mathrm{A}_{\mathrm{H}}\right)$ ') were applied. The following WBV loading regimes were defined: 12 $30 \mathrm{~Hz}$ at $0.3 \times \mathrm{g}\left(\mathrm{F}_{\mathrm{L}} \mathrm{A}_{\mathrm{H}}\right) ; 70-90 \mathrm{~Hz}$ at $0.075 \times \mathrm{g}\left(\mathrm{F}_{\mathrm{M}} \mathrm{A}_{\mathrm{M}}\right) ; 70-90 \mathrm{~Hz}$ at $0.3 \times \mathrm{g}\left(\mathrm{F}_{\mathrm{M}} \mathrm{A}_{\mathrm{H}}\right) ; 130$ $150 \mathrm{~Hz}$ at $0.043 \times \mathrm{g}\left(\mathrm{F}_{\mathrm{H}} \mathrm{A}_{\mathrm{L}}\right)$; and $130-150 \mathrm{~Hz}$ at $0.3 \times \mathrm{g}\left(\mathrm{F}_{\mathrm{H}} \mathrm{A}_{\mathrm{H}}\right)$ (Table 1 ). Each test group received 5 steps of loading. For example, for the animals of the group $\mathrm{F}_{\mathrm{M}} \mathrm{A}_{\mathrm{H}}, \mathrm{WBV}$ was applied at 70-75-80-85-90 Hz loading in a randomized way for 1 min per frequency (total loading duration of $5 \mathrm{~min}$ ). Likewise, the vibration steps for the $\mathrm{F}_{\mathrm{L}} \mathrm{A}_{\mathrm{H}}$ and $\mathrm{F}_{\mathrm{H}} \mathrm{A}_{\mathrm{H}}$ groups were 12-15-20-25-30, and 130-135-140-145-150 Hz, respectively. Groups F L A H , F м A $\mathrm{H}_{\text {and }} \mathrm{F}_{\mathrm{H}} \mathrm{A}_{\mathrm{H}}$ were loaded with the same loading acceleration but with varying loading frequencies. Groups $\mathrm{F}_{\mathrm{M}} \mathrm{A}_{\mathrm{M}}$ and $\mathrm{F}_{\mathrm{M}} \mathrm{A}_{\mathrm{H}}$ as well as groups $\mathrm{F}_{\mathrm{H}} \mathrm{A}_{\mathrm{L}}$ and $\mathrm{F}_{\mathrm{H}} \mathrm{A}_{\mathrm{H}}$ shared common loading frequency ranges but with varying loading accelerations. Vibration loading started the day following surgery ('immediate implant loading' as defined in the consensus report on the classification of loading protocols [29]) and was applied 5 days per week for either 1 or 4 weeks. WBV was applied individually, taking into account the animal's body weight. Intervals of $24 \mathrm{~h}$ between the loading sessions were respected.

Table 1

Frequency and acceleration parameters of the different loading regimes

\begin{tabular}{|l|l|l|l|l|}
\hline \multirow{2}{*}{ Group } & \multicolumn{2}{|l|}{ Frequency (Hz) } & \multicolumn{2}{l|}{ Acceleration (g) } \\
\cline { 2 - 5 } & Range & Classification & Value & Classification \\
\hline CTR & - & - & - & - \\
\hline$F_{L} A_{H}$ & $12-30$ & Low & 0.3 & High \\
\hline$F_{M} A_{M}$ & $70-90$ & Med & 0.075 & Med \\
\hline$F_{M} A_{H}$ & $70-90$ & Med & 0.3 & High \\
\hline
\end{tabular}




\begin{tabular}{|l|l|l|l|l|}
\hline \multirow{2}{*}{ Group } & \multicolumn{2}{|l|}{ Frequency (Hz) } & \multicolumn{2}{l|}{ Acceleration (g) } \\
\cline { 2 - 4 } & Range & Classification & Value & Classification \\
\hline$F_{H} A_{L}$ & $130-150$ & High & 0.043 & Low \\
\hline$F_{H} A_{H}$ & $130-150$ & High & 0.3 & High \\
\hline
\end{tabular}

CTR control, F frequency, A acceleration, L low, $\mathrm{M}$ medium, $\mathrm{H}$ high

\section{Specimen Preparation and Analysis}

At sacrifice, the bone-implant blocks were dissected, fixated in a $\mathrm{CaCO}_{3}$-buffered formalin solution and dehydrated in increasing concentrations of alcohol. After dehydration, the samples were embedded in polymethylmethacrylate. The embedded samples were cut by a diamond saw (Leica SP 1600, Leica Microsystems Nussloch, Germany) along the axis of the tibia and the implant. Three sections per sample could be obtained, out of which the most central ones were polished to a final thickness of 20-30 $\mu \mathrm{m}$ (Exakt $400 \mathrm{CS}$, Exakt

Technologies Inc., Norderstedt, Germany). Subsequently, the sections were stained with Van Gieson's picrofuchsin red to visualize the mineralized bone tissue and with Stevenel's blue to visualize the fibrous tissue.

The histological and histomorphometrical analyses were performed using a light microscope with a magnification of $\times 100$ (Leica Laborlux, Wetzlar, Germany). The samples were scanned with a high-sensitivity video camera (AxioCam Mrc5, Zeiss, Göttingen, Germany) at an image resolution of $1.22 \mu \mathrm{m} /$ pixel. The histomorphometrical analyses were performed via digital imaging processing (Axiovision 4.0, Zeiss, Göttingen, Germany). The following analyses were performed (Fig. 2):

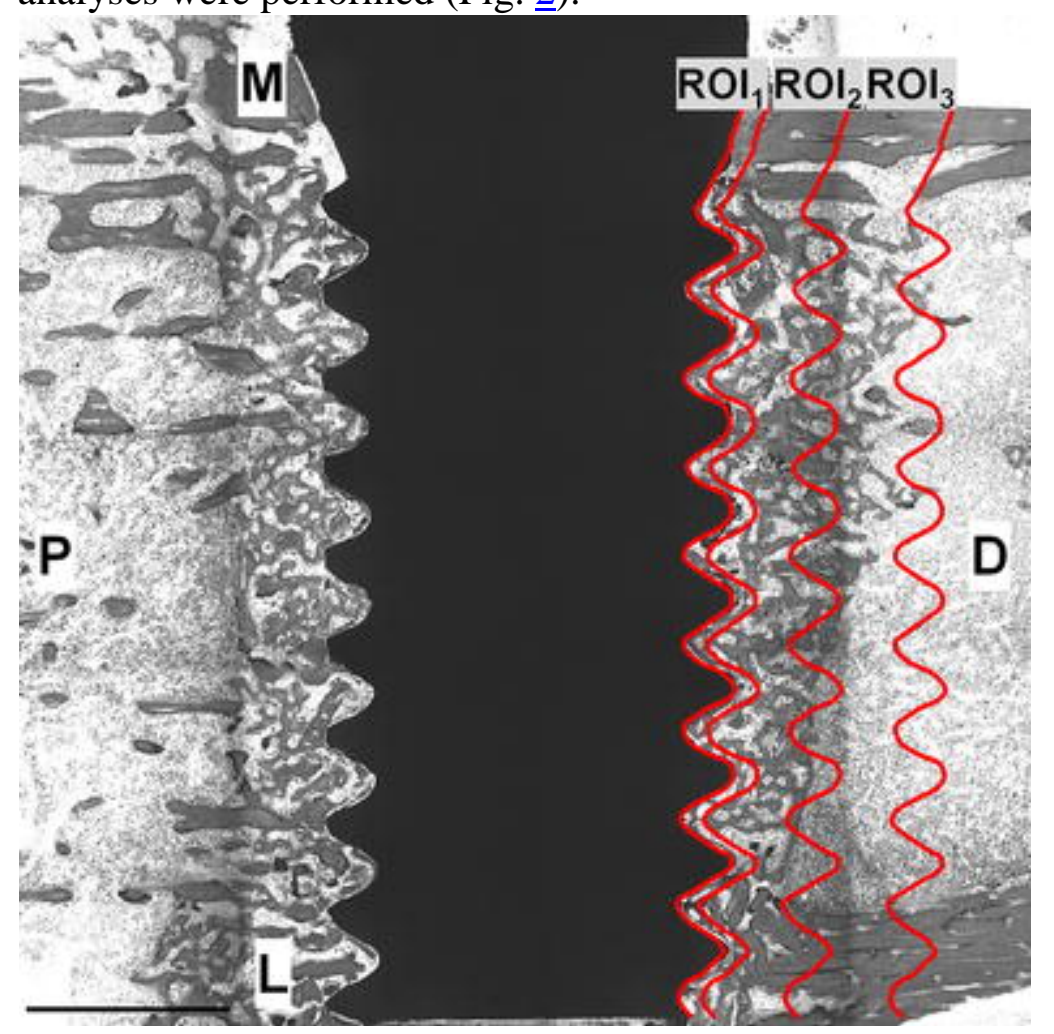

Fig. 2

Illustration of the 3 defined regions of interest (ROI) for histomorphometrical analysis of the peri-implant bone reaction (BV/TV bone volume relative to tissue volume) in cortex and medulla: 0-100 $\mu \mathrm{m}$ (BV/TV_ROI 1 ), 100-500 $\mu \mathrm{m}\left(\mathrm{BV} / \mathrm{TV} \_\mathrm{ROI}_{2}\right)$ and 500-1,000 $\mu \mathrm{m}$ 
(BV/TV_ROI 3 ) wide zones relative to the implant surface. Scale bar $1 \mathrm{~mm}$. P proximal, D distal, M medial, L lateral

(i)

Bone-to-implant contact (BIC, \%): summation of the lengths of contact between bone and implant/implant length extending from the most medial till the most lateral BIC point;

\section{(ii)}

Peri-implant bone volume relative to tissue volume (BV/TV; \%): the amount of bone in a specific reference area. Three different regions of interest (ROI) were defined: 0-100 $\mu \mathrm{m}$ (BV/TV_ROI 1 ), 100-500 $\mu \mathrm{m}\left(\mathrm{BV} / \mathrm{TV} \_\mathrm{ROI}_{2}\right)$ and 500-1,000 $\mu \mathrm{m}\left(\mathrm{BV} / \mathrm{TV} \_\mathrm{ROI}_{3}\right) \mathrm{zones}$ extending from the implant surface. The areas encompassed the peri-implant tissues from medial till lateral cortex.

BIC and BV/TV measurements were performed at both proximal and distal implant sides. Images were pre-processed via a customized script for tracing BIC and BV/TV [24, 30]. The colour images were then binarized using an automatic threshold based on the histogram frequency distribution of grey levels, and subsequently computed. The reproducibility of the measurements performed by 2 examiners was evaluated. As this inter-examiner variation was very limited, one examiner continued the measurements.

\section{Statistical Analysis}

Two-way ANOVA and post hoc Tukey HSD tests were performed to evaluate differences between the 2 experimental periods and between the 6 loading modes (SPSS ver. 13.0, Chicago, IL, USA). The significance level was set at $\mathrm{p}<0.05$.

\section{Results}

All but 1 implant healed uneventfully. The latter implant (unloaded, 1 week CTR-group) was excluded from the study.

\section{Histological Observations}

A representative example of an unloaded versus WBV loaded implant for 1 and 4 weeks of loading is shown in Fig. $\underline{3}$. An osteogenic response at the implant surface and in the implant vicinity could be observed histologically already 1 week after implant installation. At the cortical level, bone remodelling with necrotic bone remnants as well as newly formed bone trabeculae was seen. In the medullar region - a region devoid of bone tissue prior to implant installation — newly formed tissue was observed around the implant, consisting of fibrovascular stroma with bone trabeculae. The bone formation occurred exclusively via a primary repair sequence, without a cartilaginous intermediary. In unloaded conditions, the amount of newly formed bone along the implant surface decreased with increasing distance from the cortex. This reflects the process of appositional bone growth, originating from the endosteal cortical trabeculae. This was observed in particular at the distal side, the side without native metaphyseal bone trabeculae. Owing to the osteoconductivity of a titanium implant, the peri-implant bone growth extended further towards the middle of the implant. In case of WBV loading, however, it was observed that the width of the peri-implant bone collar along the entire implant length was more uniform, suggesting that cells other (i.e. progenitor cells) than resident bone cells, in response to mechanical stimulation, contributed to the bone 
formation. Indirect implant loading through WBV for 1 week resulted in a non-site-dependent anabolic bone response at the medullar level.

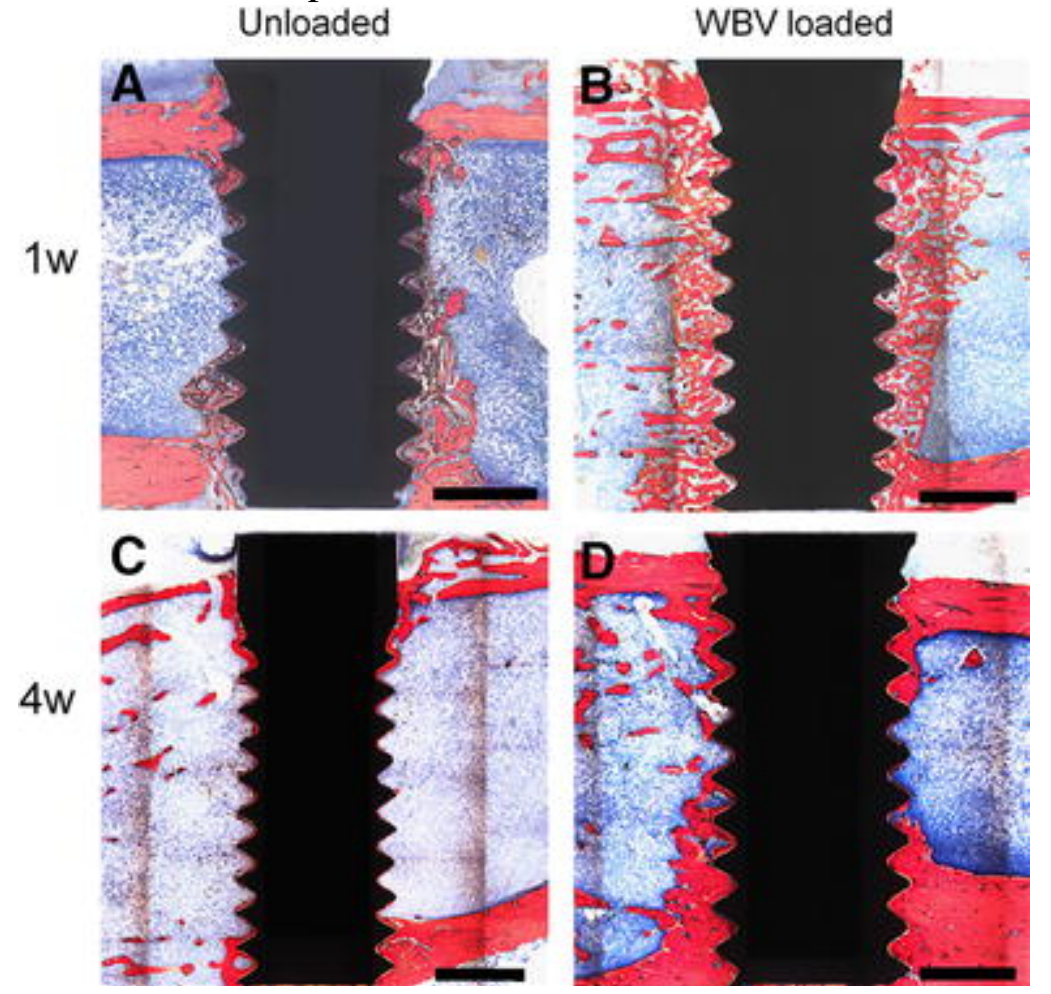

Fig. 3

Representative image of unloaded and WBV loaded implants from the 1 and the 4-week experimental period. Scale bar $1 \mathrm{~mm}$. Bone formation took place adjacent to the implant in the medulla after 1 week of healing for both unloaded (a) and loaded (b) implants.

Reorganization of the newly formed peri-implant bone, indicative for bone remodelling, led to dense bone adjacent to both unloaded (c) and WBV loaded (d) implants

After 4 weeks of unloaded or loaded healing, irrespective of the applied WBV loading regime, the newly formed bone had matured and was reorganized into lamellar, i.e. an orderly deposition of the collagen fibres as observed by microscopy, bone tissue. At the same time, less cuboidal-shaped osteoblasts were noticed in both the cortical and medullar region, indicative for a restricted bone formation activity. Furthermore, the amount of the lamellar bone deposited onto the implant surface was found to be dependent on the loading protocol. In the absence of loading, a thin bone 'shell' of uniform thickness along the entire implant was observed. In contrast, in response to WBV loading, a striking increase in the width of the peri-implant bone could be discerned: a thick bone 'collar' around the implant was formed, starting from both the medial and lateral cortex and almost connecting.

\section{Histomorphometrical Analysis}

BIC was significantly influenced by WBV loading as well as by the duration of the loading period, without interaction between the factors (ANOVA; $\mathrm{p}<0.0001$ ) (Table 2 ). BIC increased over time (Fig. 4). Post hoc analysis exploring differences in BIC between the different loading regimes revealed that BIC in each WBV loaded group was significantly higher compared to the unloaded group (Tukey HSD test; $\mathrm{p}<0.0001$ ). Furthermore, the loading regimes at medium and high frequency combined with a high acceleration protocol ( $\mathrm{F}$ ${ }_{\mathrm{M}} \mathrm{A}_{\mathrm{H}}$ and $\mathrm{F}_{\mathrm{H}} \mathrm{A}_{\mathrm{H}}$ ) resulted in the highest BIC values, which were significantly different from BIC values obtained after WBV stimulation at low frequency with high acceleration $\left(F_{L} A_{H}\right)$ 
and at medium frequency with medium acceleration ( $\mathrm{F}_{\mathrm{M}} \mathrm{A}_{\mathrm{M}}$ ) (Tukey HSD test; $\mathrm{p}<0.02$ and $\mathrm{p}<0.005$, respectively) (Fig. $\underline{4}$ ).

Table 2

ANOVA results of the effect of the independent variables (i.e. the duration of the experimental period, the loading mode and their interaction) on the dependent variables (i.e. $\mathrm{BIC}$ and $\mathrm{BF}$ )

\begin{tabular}{|l|l|l|l|}
\hline \multicolumn{1}{|l|}{} & Duration & Loading_Mode & Duration*Loading_Mode \\
\hline BIC & $\mathrm{p}<0.0001$ & $\mathrm{p}<0.0001$ & $\mathrm{p}=0.190$ \\
\hline BV/TV_ROI & $\mathrm{p}<0.0001$ & $\mathrm{p}<0.001$ & $\mathrm{p}=0.962$ \\
\hline BV/TV_ROI & $\mathrm{p}<0.0001$ & $\mathrm{p}=0.519$ & $\mathrm{p}=0.753$ \\
\hline BV/TV_ROI & $\mathrm{p}<0.0001$ & $\mathrm{p}=0.555$ & $\mathrm{p}=0.524$ \\
\hline
\end{tabular}

BIC bone-to-implant contact, BV/TV peri-implant bone volume relative to tissue volume, ROI region of interest

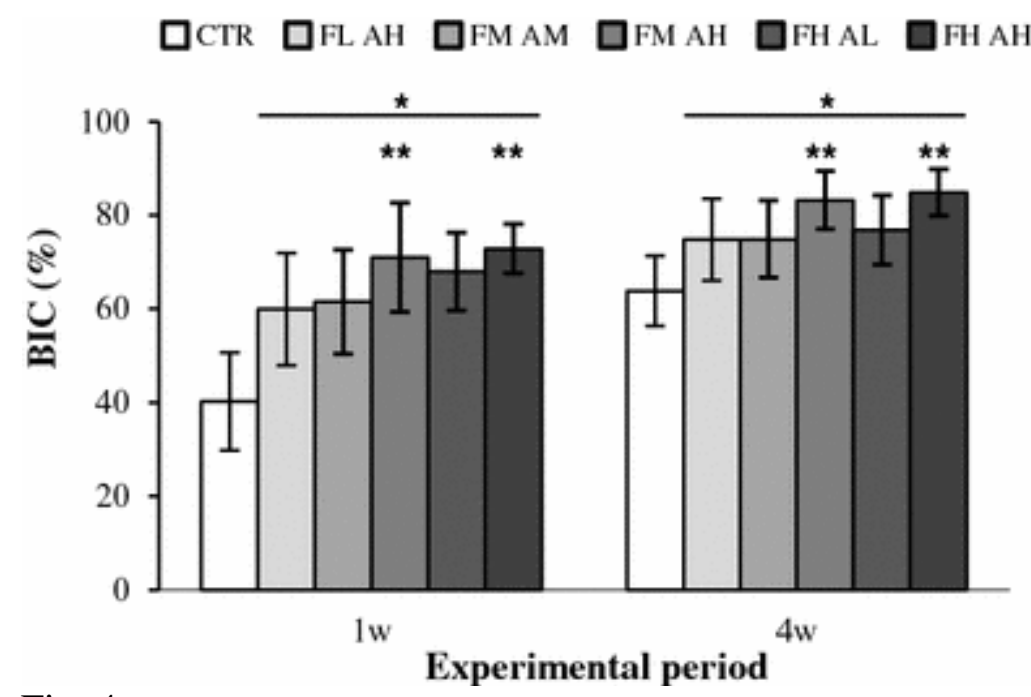

Fig. 4

Histomorphometrical results of BIC. Means and standard deviations for the 2 experimental terms and for the different loading conditions are shown. *Significant different versus control group (CTR); **Significant different versus $\mathrm{F}_{\mathrm{L}} \mathrm{A}_{\mathrm{H}}$ and $\mathrm{F}_{\mathrm{m}} \mathrm{A}_{\mathrm{M}}$ (Post hoc Tukey HSD test) The peri-implant bone formation reaction to WBV loading was significantly influenced by the duration of the loading term, with a decrease over time (ANOVA; $\mathrm{p}<0.0001)$. Furthermore, $\mathrm{BV} / \mathrm{TV}$ was significantly influenced by WBV loading, but solely in the region closest to the implant surface (BV/TV_ROI 1 ) (ANOVA; p < 0.001) (Table 2). No interaction was found between the duration and the loading mode factors. In contrast to BIC where an overall significant increase was found between WBV loaded and unloaded implants, post hoc analyses revealed selected increases for the peri-implant BV/TV in response to WBV loading (Tukey HSD test; $\mathrm{p}<0.02$ for $\mathrm{F}_{\mathrm{L}} \mathrm{A}_{\mathrm{H}}$ and $\mathrm{F}_{\mathrm{H}} \mathrm{A}_{\mathrm{M}}$, and $\mathrm{p}<0.001$ for $\mathrm{F}_{\mathrm{M}} \mathrm{A}_{\mathrm{H}}$ and $\mathrm{F}_{\mathrm{H}} \mathrm{A}_{\mathrm{H}}$ ) (Fig. $\underline{5}$ ). No significant differences for BV/TV_ROI 1 were found between $\mathrm{F}_{\mathrm{M}} \mathrm{A}_{\mathrm{M}}$ loaded and unloaded control implants. Moreover, likewise the BIC results, the highest BV/TV responses were found for the loading regimes at medium and high frequency combined with a high acceleration protocol ( $\mathrm{F}_{\mathrm{M}} \mathrm{A}_{\mathrm{H}}$ and $\left.\mathrm{F}_{\mathrm{H}} \mathrm{A}_{\mathrm{H}}\right)$. These differed significantly from the results of the $\mathrm{F}_{\mathrm{m}} \mathrm{A}$ м loading protocol (Tukey HSD test; $\mathrm{p}<0.005$ and $\mathrm{p}<0.001$, respectively)

(Fig. 므). 


\section{A $\square$ वTR $\square$ FlaH $\square$ FM AM $\square$ FM AH $\square$ FHAL $\square$ FH AH}

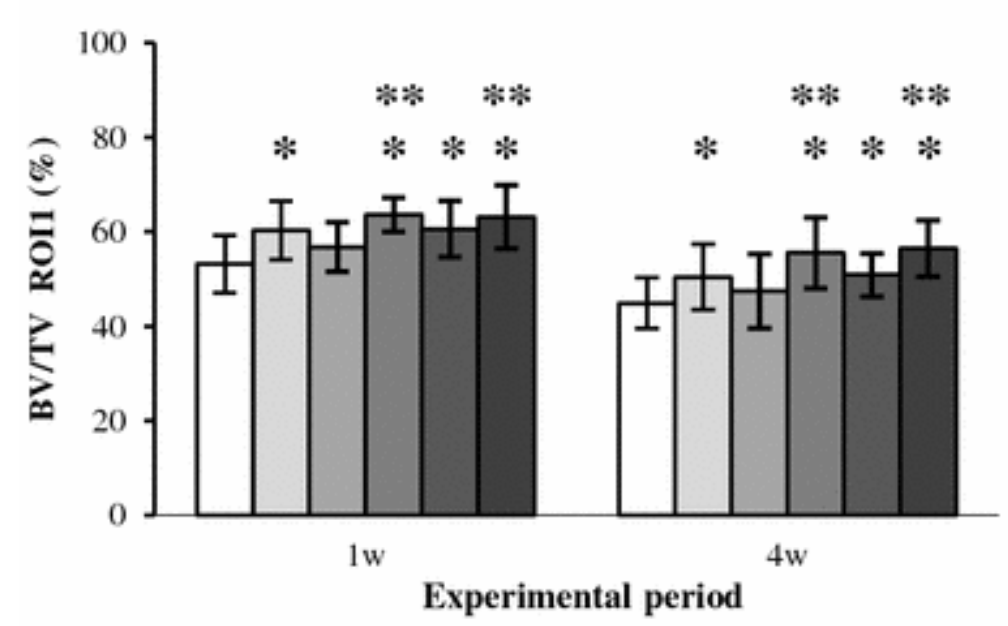

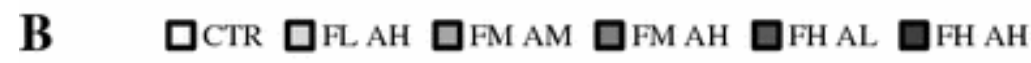

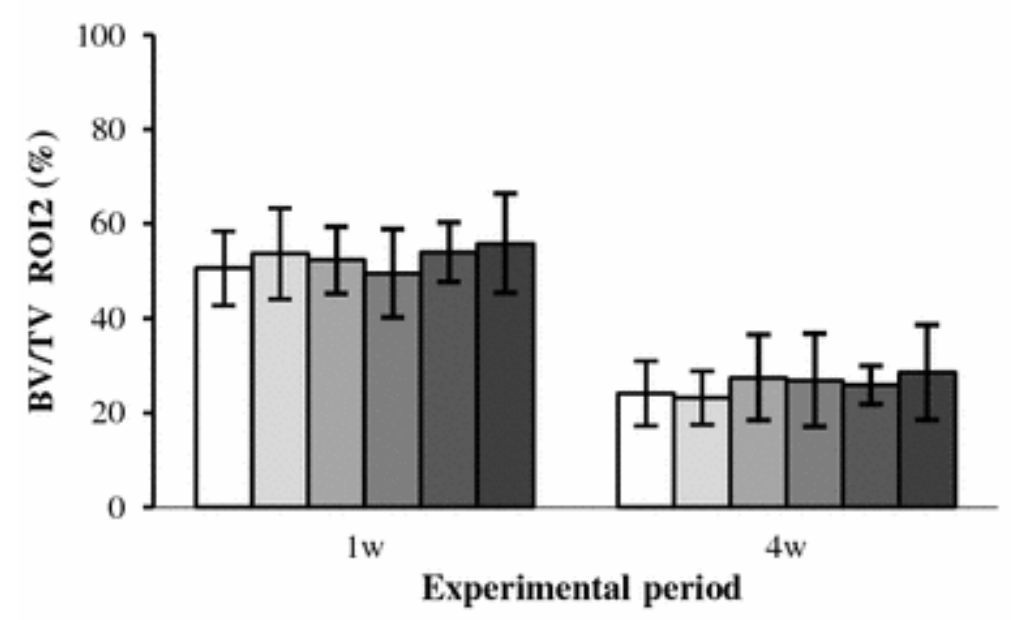

C $\square$ Ctr $\square$ F AH $\square$ FM AM $\square$ FMAH $\square$ FHAL $\square$ FHAH

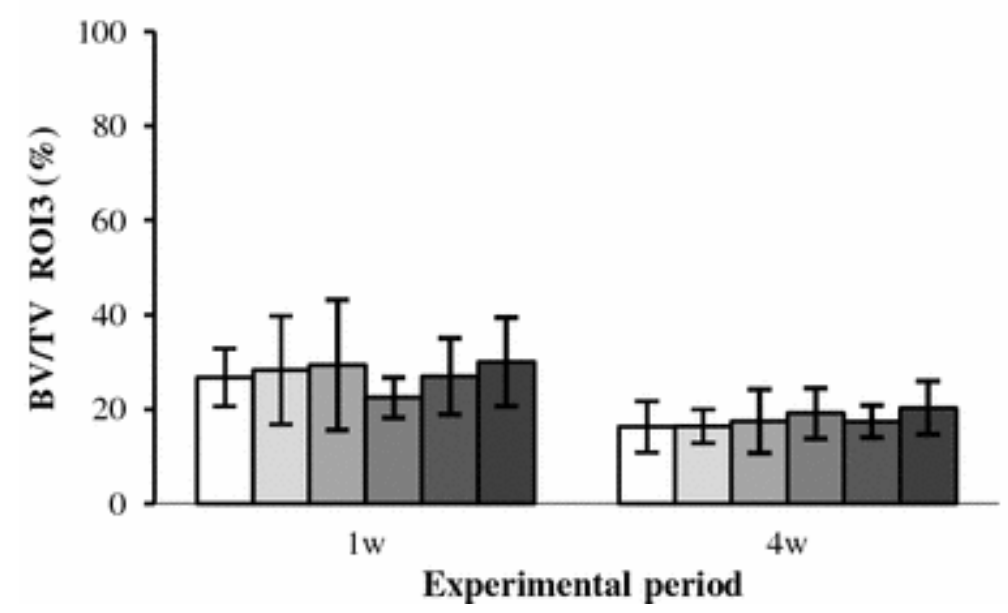

Fig. 5

Histomorphometrical results of BV/TV for the 3 regions of interest $(\mathrm{a}-\mathrm{c})$. Means and standard deviations for the 2 experimental terms and for the different loading conditions are shown. An asterisk denotes a statistically significant difference relative to the unloaded group (CTR). A 
double asterisk denotes a statistically significant difference relative to the $\mathrm{F}_{\mathrm{M}} \mathrm{A}_{\mathrm{M}}$ (Post hoc Tukey HSD test)

\section{Discussion}

The present study aimed to analyse the role of particular vibration parameters on the bone response around integrating titanium implants. The provided evidence showed that the extent of the bone reaction to WBV that depends on the characteristics of the composing parameters $[\underline{4}, \underline{20}-22]$ was anticipated for the implant osseointegration setting in the present study. More in particular, the constituting parameters frequency and acceleration on the bone tissue kinetic response around titanium implants were under investigation. Frequencies of 12-30, 70-90 and $130-150 \mathrm{~Hz}$, and accelerations of $0.043 \times \mathrm{g}, 0.075 \times \mathrm{g}$ and $0.3 \times \mathrm{g}$ were applied. It was hypothesized that (i) WBV has an anabolic effect on implant osseointegration and that (ii) the loading regime with the highest frequency and acceleration results in the most pronounced constructive peri-implant bone reaction.

Mechanical loading plays a pivotal role in bone homeostasis. Bone's sensitivity to mechanical demands in the negative and positive direction is illustrated by disuse and exercise studies, respectively [31, 32]. At the same time, it is well known that bone has a constant level of activity, aiming to keep bone tissue strains at an optimal level by altering bone structure designated as remodelling [33]. In response to injury or biomaterial installation, bone healing (renewed modelling) precedes the bone remodelling. The response to the trauma of inserting a screw in the tibial bone was on the one hand cortical bone remodelling, and on the other hand medullar trauma-induced membranous bone formation with subsequent remodelling. The new bone formation is important for the strength of screw fixation, and increased bone formation at early stages in the incorporation process may provide a better long-term prognosis [34]. The findings revealed that the least marked bone apposition onto the implant (quantified by 'BIC') was recorded when the rats were normal weight bearing (unloaded group), resulting in a retarded and a depreciated implant osseointegration compared to all tested loading regimes. Furthermore, an anabolic medullar bone response to WBV loading in the implants' vicinity (measured as 'peri-implant bone volume over tissue volume') was observed, reflecting that this peri-implant modelling- and remodelling-based bone formation is noticeable influenced by vibration loading. These findings confirm the amply provided evidence for an enhanced implant osseointegration through mechanical loading [35-38], and the corroborating evidence for the positive effect of LMHF loading on titanium implant osseointegration [ $\underline{16}-\underline{18}, \underline{24}]$. The 1st hypothesis-i.e. WBV loading is anabolic for titanium implant osseointegration-was herewith sustained.

Analogous to the findings of the pilot experiments of the authors' group [ $\underline{16}, \underline{24}]$, a significant decrease in peri-implant bone volume with increased time lapse was noted. Furthermore, the amount of medullar callus tissue declined with extending distance from the implant surface. These findings illustrate the progressive stages of ossification of the repair tissue which was formed by the osteoprogenitor cells in the marrow, the endosteal surface and the adjacent trabeculae [39], in interplay with the osteoconductive property of titanium [40]. Finally, differences between loaded and unloaded samples in this medullar bone formation were observed. Absence of stimulation resulted in the removal of the newly formed bone in this area and maximal reestablishment of the medullary canal, whereas loading preserved the bone. As these loading-related differences were significant for the reference area closest to the implant surface $\left(\mathrm{ROI}_{1}\right)$, and not for the distant areas $\mathrm{ROI}_{2}$ and $\mathrm{ROI}_{3}$, it is suggested that the loading, although applied indirectly through WBV — and not directly through direct implant loading-exerted its effect via the titanium implant and created site-specific mechanical 
conditions. The local mechanical environment resulted in loading stimulus perception by differentiating interfacial tissues rather than by the established distant tissue.

In order to gain a better understanding into the contribution of the component(s) that control the bone response to LMHF WBV loading, efforts were made on deconstructing the dynamic loading cycle into its frequency and acceleration constituent elements. Frequencies and accelerations classified as low, medium or high were assigned and combined. It was observed that the loading mode with the highest acceleration $(0.3 \times \mathrm{g})$, combined with medium $(70$ $90 \mathrm{~Hz}$ ) or high (130-150 Hz) frequency (groups $\mathrm{F}_{\mathrm{M}} \mathrm{A}_{\mathrm{H}}$ and $\mathrm{F}_{\mathrm{H}} \mathrm{A}_{\mathrm{H}}$, respectively), resulted in significantly more bone apposition onto the implant (BIC) compared to the corresponding loading mode at low frequency $\left(\mathrm{F}_{\mathrm{L}} \mathrm{A}_{\mathrm{H}} ; 12-30 \mathrm{~Hz}\right.$ at $\left.0.3 \times \mathrm{g}\right)$ and to the medium frequency and acceleration protocol ( $\mathrm{F}_{\mathrm{M}} \mathrm{A}$ м; 70-90 Hz; 0.075×g). These data establish bone's ability to discriminate between vibration frequencies when loading at high acceleration, and indicate that focusing on the loading bouts frequency and on the duration for a specific frequency is an attractive strategy for the optimization of WBV intervention in biomaterial integration. The $F$ ${ }_{\mathrm{M}} \mathrm{A}_{\mathrm{H}}$ and $\mathrm{F}_{\mathrm{H}} \mathrm{A}_{\mathrm{H}}$ loading regimes were also the best performing in terms of formation of bone adjacent to the implant surface (bone volume in $\mathrm{ROI}_{1}$ ), but solely significantly differing from $\mathrm{F}_{\mathrm{m}} \mathrm{A}$ м. Our 2nd hypothesis-i.e. the loading regime with the highest frequency and acceleration will result in the most pronounced constructive peri-implant bone reactioncould only partly be confirmed: the loading regime at medium frequency with high acceleration is as potent as the $\mathrm{F}_{\mathrm{H}} \mathrm{A}_{\mathrm{H}}$ protocol for enhancing titanium implant osseointegration.

The degree by which variations in the parameters defining a WBV intervention alter the efficacy of the low-level mechanical signals for the implant setting is now starting to become unravelled. However, the importance of the host bone characteristics, i.e. the quality and the related vascularisation, has not been profoundly recognized in this context. It has been repeatedly shown that WBV can serve as an anabolic signal to a skeleton, even upon the withdrawal of oestrogen $[\underline{6}, \underline{8}, \underline{12}, \underline{17}, \underline{20}, \underline{41}]$. While interference of osteoporosis with the implant-tissue integration process has been evidenced [ $\underline{42}, \underline{43}]$, only 2 studies were published on the effect of LMHF mechanical vibration on peri-implant bone volume in osteoporotic rats $[\underline{17}, \underline{18}]$. Future studies probing the interdependence of WBV mechanical parameters and covering the host bone properties will provide important clues towards identification of the physical mechanisms by which WBV perturbs bone's cellular activity.

Several limitations of this study need to be addressed. We did not do any measurements to shed light on the mechanical fixation of screws, nor of the induced strain environment. This information, particularly at the initial phases of implant osseointegration, would be valuable for the interpretation and further optimization of LMHF loading protocols. Also, identification of the sites of active mineralization of the peri-implant bone relative to the applied loading regime, by use calcium-binding fluorochromes, was not performed for practical reasons, but would provide relevant information regarding accretion and direction of bone formation at the implant site in response to LMHF mechanical loading. Furthermore, not all possible combinations of 'frequency' and 'acceleration' ( $\mathrm{L}-\mathrm{M}-\mathrm{H})$ for the 2 experimental periods (14 weeks) were investigated, thereby rendering the full exploration of their interaction effects in a 3-way ANOVA and consequently of their selective individual effects on the peri-implant bone incomplete. Finally, the evidence provided in the present and in previous studies on the positive effect of high-frequency loading on implant osseointegration is mainly derived from tissue level findings. Statistically significant differences for the BIC and BV/TV parameters evaluating implant osseointegration in response to WBV were recorded, though rather modest. Therefore, bone generation in peri-implant bone regeneration in response to WBV loading needs to be further explored in terms of the implicated molecular regulatory mechanisms. Advanced gene and protein expression approaches may contribute towards an 
understanding of the mechanisms involved in bone mechanotransduction at the in vivo titanium bone-implant interface. The revelation that AMP-activated protein kinase (AMPK) signalling - a key sensing mechanism in the regulation of cellular energy homeostasiswhich is implicated in bone metabolism renders AMPK signalling as an attractive pathway to explore in skeletal physiology in response to loading, and in particular in bone disease states (such as osteoporosis and diabetes) [44].

In summary, vibration loading is not only part of athletes training, but can also be a nonpharmaceutical tool in bone regeneration and biomaterial integration. One of the factors ensuring effective vibration stimulation is a set of optimal vibration parameters. The observed findings suggest that titanium implant osseointegration is accelerated and enhanced with increasing frequency and acceleration. Therefore, high frequencies and acceleration protocols might be recommended. Translation into the clinical titanium implant setting could be realized through the development of miniature vibration devices and assessment of its effect on the peri-implant bone for different application modes such as incorporated into a jaw brace or in direct connection with the prosthesis. However, in order to avoid the use of high frequencies which are sometimes unpleasant for certain individuals, the vibration characteristics could be modulated by combining moderate frequencies with higher amplitudes and, based on our finding, may still expect the same outcome of the applied protocol.

Acknowledgments

This work was supported by the Research Council of the Katholieke Universiteit Leuven (Belgium) (OT07/059) and the Fund for Scientific Research Flanders (G.0726.09). We would like to thank Dr. H. van Lenthe for his scientific advice.

Conflict of interest

The authors declare that they have no conflict of interest, financial or otherwise.

Human and Animal Rights and Informed Consent

The research protocol was approved by the local ethical committee for laboratory animal research of the Katholieke Universiteit Leuven (P029/2008), and was performed according to the Belgian animal welfare regulations and guidelines.

\section{References}

1 .

Judex S, Gupta S, Rubin C (2009) Regulation of mechanical signals in bone. Orthod Craniofac Res 12:94-104

2.

Rubin C, Turner AS, Bain S, Mallinckrodt C, McLeod K (2001) Anabolism. Low mechanical signals strengthen long bones. Nature 412:603-604

3.

Goodship AE, Lawes TJ, Rubin CT (2009) Low-magnitude high-frequency mechanical signals accelerate and augment endochondral bone repair: preliminary evidence of efficacy. $\mathrm{J}$ Orthop Res 27:922-930

4.

Hwang SJ, Lublinsky S, Seo YK, Kim IS, Judex S (2009) Extremely small-magnitude accelerations enhance bone regeneration: a preliminary study. Clin Orthop Relat Res 467:1083-1091

5. 
Omar H, Shen G, Jones AS, Zoellner H, Petocz P, Darendeliler MA (2008) Effect of low magnitude and high frequency mechanical stimuli on defects healing in cranial bones. J Oral Maxillofac Surg 66:1104-1111

6.

Sehmisch S, Galal R, Kolios L, Tezval M, Dullin C, Zimmer S, Stuermer KM, Stuermer EK (2009) Effects of low-magnitude, high-frequency mechanical stimulation in the rat osteopenia model. Osteoporos Int 20:1999-2008

7.

Shi HF, Cheung WH, Qin L, Leung AH, Leung KS (2010) Low-magnitude high-frequency vibration treatment augments fracture healing in ovariectomy-induced osteoporotic bone. Bone 46:1299-1305

8.

Tezval M, Biblis M, Sehmisch S, Schmelz U, Kolios L, Rack T, Stuermer KM, Stuermer EK (2011) Improvement of femoral bone quality after low-magnitude, high-frequency mechanical stimulation in the ovariectomized rat as an osteopenia model. Calcif Tissue Int 88:33-40

9.

Gilsanz V, Wren TA, Sanchez M, Dorey F, Judex S, Rubin C (2006) Low-level, highfrequency mechanical signals enhance musculoskeletal development of young women with low BMD. J Bone Miner Res 21:1464-1474

10 .

Rubin C, Recker R, Cullen D, Ryaby J, McCabe J, McLeod K (2004) Prevention of postmenopausal bone loss by a low-magnitude, high-frequency mechanical stimuli: a clinical trial assessing compliance, efficacy, and safety. J Bone Miner Res 19:343-351

11.

Rubin CT, Sommerfeldt DW, Judex S, Qin Y (2001) Inhibition of osteopenia by low magnitude, high-frequency mechanical stimuli. Drug Discov Today 6:848-858

12.

Verschueren SM, Roelants M, Delecluse C, Swinnen S, Vanderschueren D, Boonen S (2004) Effect of 6-month whole body vibration training on hip density, muscle strength, and postural control in postmenopausal women: a randomized controlled pilot study. J Bone Miner Res 19:352-359

13.

Ward K, Alsop C, Caulton J, Rubin C, Adams J, Mughal Z (2004) Low magnitude mechanical loading is osteogenic in children with disabling conditions. J Bone Miner Res 19:360-369

14.

Berglundh T, Abrahamsson I, Lang NP, Lindhe J (2003) De novo alveolar bone formation adjacent to endosseous implants. Clin Oral Implants Res 14:251-262

15.

Mavrogenis AF, Dimitriou R, Parvizi J, Babis GC (2009) Biology of implant osseointegration. J Musculoskelet Neuronal Interact 9:61-71

16.

Ogawa T, Zhang X, Naert I, Vermaelen P, Deroose CM, Sasaki K, Duyck J (2011) The effect of whole-body vibration on peri-implant bone healing in rats. Clin Oral Implants Res 22:302307

17.

Akca K, Sarac E, Baysal U, Fanuscu M, Chang TL, Cehreli M (2007) Micro-morphologic changes around biophysically stimulated titanium implants in ovariectomized rats. Head Face Med 3:28

18. 
Chen B, Li Y, Xie D, Yang X (2012) Low-magnitude high-frequency loading via whole body vibration enhances bone-implant osseointegration in ovariectomized rats. J Orthop Res 30:733-739

19.

Castillo AB, Alam I, Tanaka SM, Levenda J, Li J, Warden SJ, Turner CH (2006) Lowamplitude, broad-frequency vibration effects on cortical bone formation in mice. Bone 39:1087-1096

20.

Judex S, Lei X, Han D, Rubin C (2007) Low-magnitude mechanical signals that stimulate bone formation in the ovariectomized rat are dependent on the applied frequency but not on the strain magnitude. J Biomech 40:1333-1339

21.

Oxlund BS, Ortoft G, Andreassen TT, Oxlund H (2003) Low-intensity, high-frequency vibration appears to prevent the decrease in strength of the femur and tibia associated with ovariectomy of adult rats. Bone 32:69-77

22.

Rubin CT, McLeod KJ (1994) Promotion of bony ingrowth by frequency-specific, lowamplitude mechanical strain. Clin Orthop Relat Res 298:165-174

23.

Rubinacci A, Marenzana M, Cavani F, Colasante F, Villa I, Willnecker J, Moro GL, Spreafico LP, Ferretti M, Guidobono F, Marotti G (2008) Ovariectomy sensitizes rat cortical bone to whole-body vibration. Calcif Tissue Int 82:316-326

24.

Ogawa T, Possemiers T, Zhang X, Naert I, Chaudhari A, Sasaki K, Duyck J (2011) Influence of whole-body vibration time on peri-implant bone healing: a histomorphometrical animal study. J Clin Periodontol 38:180-185

25.

Cardinale M, Wakeling J (2005) Whole body vibration exercise: are vibrations good for you? Br J Sports Med 39:585-589

26.

Luo J, McNamara B, Moran K (2005) The use of vibration training to enhance muscle strength and power. Sports Med 35:23-41

27.

Pollock RD, Woledge RC, Mills KR, Martin FC, Newham DJ (2010) Muscle activity and acceleration during whole body vibration: effect of frequency and amplitude. Clin Biomech (Bristol, Avon) 25:840-846

28.

van der Jagt OP, van der Linden JC, Waarsing JH, Verhaar JA, Weinans H (2012) Lowmagnitude whole body vibration does not affect bone mass but does affect weight in ovariectomized rats. J Bone Miner Metab 30:40-46

29.

Esposito M, Grusovin MG, Achille H, Coulthard P, Worthington HV (2009) Interventions for replacing missing teeth: different times for loading dental implants. Cochrane Database Syst Rev CD003878

30 .

Duyck J, Corpas L, Vermeiren S, Ogawa T, Quirynen M, Vandamme K, Jacobs R, Naert I (2010) Histological, histomorphometrical, and radiological evaluation of an experimental implant design with a high insertion torque. Clin Oral Implants Res 21:877-884 31. 
Kontulainen S, Sievanen H, Kannus P, Pasanen M, Vuori I (2003) Effect of long-term impactloading on mass, size, and estimated strength of humerus and radius of female racquet-sports players: a peripheral quantitative computed tomography study between young and old starters and controls. J Bone Miner Res 18:352-359

32.

Vico L, Collet P, Guignandon A, Lafage-Proust MH, Thomas T, Rehaillia M, Alexandre C (2000) Effects of long-term microgravity exposure on cancellous and cortical weight-bearing bones of cosmonauts. Lancet 355:1607-1611

33.

Frost HM (2004) A 2003 update of bone physiology and Wolff's Law for clinicians. Angle Orthod 74:3-15

34.

Ryd L, Albrektsson BE, Carlsson L, Dansgard F, Herberts P, Lindstrand A, Regner L, Toksvig-Larsen S (1995) Roentgen stereophotogrammetric analysis as a predictor of mechanical loosening of knee prostheses. J Bone Joint Surg Br 77:377-383

35.

De Smet E, Jaecques SV, Wevers M, Jansen JA, Jacobs R, Sloten JV, Naert IE (2006) Effect of controlled early implant loading on bone healing and bone mass in guinea pigs, as assessed by micro-CT and histology. Eur J Oral Sci 114:232-242

36.

Duyck J, Vandamme K, Geris L, Van OH, De CM, Vandersloten J, Puers R, Naert I (2006) The influence of micro-motion on the tissue differentiation around immediately loaded cylindrical turned titanium implants. Arch Oral Biol 51:1-9

37.

Leucht P, Kim JB, Wazen R, Currey JA, Nanci A, Brunski JB, Helms JA (2007) Effect of mechanical stimuli on skeletal regeneration around implants. Bone 40:919-930

38.

Zhang X, Vandamme K, Torcasio A, Ogawa T, van Lenthe GH, Naert I, Duyck J (2012) In vivo assessment of the effect of controlled high- and low-frequency mechanical loading on peri-implant bone healing. J R Soc Interface 9:1697-1704

39.

Xu B, Zhang J, Brewer E, Tu Q, Yu L, Tang J, Krebsbach P, Wieland M, Chen J (2009) Osterix enhances BMSC-associated osseointegration of implants. J Dent Res 88:1003-1007 40.

Le Guehennec L, Soueidan A, Layrolle P, Amouriq Y (2007) Surface treatments of titanium dental implants for rapid osseointegration. Dent Mater 23:844-854

41.

Rubin C, Judex S, Qin YX (2006) Low-level mechanical signals and their potential as a nonpharmacological intervention for osteoporosis. Age Ageing 35(Suppl 2):ii32-ii36

42.

Ozawa S, Ogawa T, Iida K, Sukotjo C, Hasegawa H, Nishimura RD, Nishimura I (2002)

Ovariectomy hinders the early stage of bone-implant integration: histomorphometric, biomechanical, and molecular analyses. Bone 30:137-143

43.

Vandamme K, Holy X, Bensidhoum M, Logeart-Avramoglou D, Naert IE, Duyck JA, Petite $\mathrm{H}$ (2011) In vivo molecular evidence of delayed titanium implant osseointegration in compromised bone. Biomaterials 32:3547-3554

44.

Jeyabalan J, Shah M, Viollet B, Chenu C (2012) AMP-activated protein kinase pathway and bone metabolism. J Endocrinol 212:277-290 